\title{
ATTITUDE TOWARDS LEARNING STYLES AND THINKING STYLES OF MENTAL HEALTH
}

KEY WORDS: Learning styles, Thinking styles, Mental Health

\section{T. S. Clara}

Ph.D. Research Scholar, Alagappa University College Of education, Alagappa University, Karaikudi.

\section{Dr. M. Suganthi*}

Assistant Professor, Alagappa University College Of Education, Alagappa University, Karaikudi. *Corresponding Author

\begin{abstract}
The number of children reporting mental health problems has increased dramatically in recent years, and the signs are that it will continue to rise further. For most children, their first steps into education will be some of the most challenging times they have faced. Most will be dealing with newfound independence, along with the challenges of balancing their academic work, new financial pressures, and building new social relationships. Children, like anybody else, differ from each other. As children, they differ in their preferred mode of learning, i.e. their preferred modes in gathering and thinking about information. The objective of this study was to examine whether children's learning styles, thinking styles, and attitudes can be used as predictors of their mental health.
\end{abstract}

\section{INTRODUCTION}

Education plays a significant role in all areas from personal to social development. Every aspect of society is changing day by day therefore to maintain pace with the changing society, education is the only appropriate tool. Education is key to development and tries to create a peaceful social environment. Education is a right that improvises lives by appropriate and supported core shared values.

Learning styles are an individual's characteristic methods of gaining knowledge, skills, and attitudes through study or experiences. Getting knowledge of students' learning methods can be very helpful for both teachers and students. The active process of learning requires identifying and understanding students learning styles. Learning style has an impact on the teaching and learning process. Students have their preferred way to recognize, retain, and retrieve information. A teacher should help the learner to recognize its preferable learning style and plan its teachings accordingly.

This era is of acute modernization and therefore a radical change in every field like scientific inventions and technological advancement. To cope up with these advancements and to fulfill the requirements of this fastchanging and developing society, people need to grow in the ability to think rationally, creatively,and thus able to express their thoughts, clearly. Independent and positive thoughts, careful and keen observation are the contributing factors of success. Thinking is one of the major aspects of cognitive behave style is neither cognition nor personality but the combination of them. Thinking style is the way a student prefers to conceive information. It also refers to the student's priority to think about information or task both during and after the learning process.

Mental health can be considered as an important factor because good intellect depends on sound mental health. Many efforts are made in schools to raise the interest, ability, personality of students. But somewhere these efforts lack behind in developing the overall personality of students and for better academic achievement. One of the major factors influencing the academic achievement of students is sound mental health. A healthy student is not only physically healthy but also mentally healthy to handle academic challenges.

\section{LEARNING STYLES}

Learning styles means that the strategies we tend to apply whenever we'd like to; focus on new and troublesome information; absorb this information through our senses; process the information and transform it into knowledge; store this data in our brains; retain the knowledge we've got a hold on.

|www.worldwidejournals.com |
Learning styles means that different strategies of learning or understanding new information, the method an individual takes in, strategies of learning or understanding new information, the method an individual takes in, understand, expresses, and remembers information.

\section{FACTORS AFFECTING LEARNING STYLES}

Some of the variables that are likely to affect the development of learning styles are:

Genetically Inherited: The particular learning style of the parent of the child is being adopted by the child is approaching a learning situation. Life experiences and demands of the environment, students develop a learning method that emphasizescertain learning abilities over other students (source: Guild and Garger, 1985)

Schooling/Educational Background: Source: Cortazzi (1997) and Jordan (1997) stated that the origin of learner style is often the student's educational background, and also their cultural background. Thus, learner's surroundings and educational background affect their preference in learning.

Gender: Gender differences in verbal style of learning are also found, where females are having an advantage over males. The female student tends to exhibit more characteristics of responsibility and a stronger preference for learning in various sociological environments than males, while male students have more competitive qualities.

Birth Order: Birth order has been studied for many years as a factor that plays an important part in influencing the learning style of students. It means that firstborn children are more independent, dominant, and authoritarian than later born. It may be because of the reason that they are not dominated by their elder brother or sister and are free to make their own decisions (Sternberg, 1997)

\section{THINIKING STYLES}

Thinking styles are defined as how a person elects the ways to do tasks according to their abilities. We manage our daily activities with our preferred style of thinking with which we feel comfortable (Source: Sternberg, 1997). He explored that it is not a conscious activity or ability rather its only involves preferences of styles consistent with one's abilities and needs (Armstrong, 2000; Cano-Garcia and Hughes, 2000; Grigorenko and Sternberg, 1997;Zhang, 2000).

FACTORS AFFECTING THINKING STYLES

Some of the variables that are likely to influence the development of thinking styles are: 
Culture: Culture is likely to be more rewarding for certain styles than for others. In some cultures, children are instructed from their younger days not to question certain religious tenets. In some societies, children are encouraged to question much of what they are taught.

Gender: Males are more typically described as adventurous, individualistic, innovative, and progressive. Females are more often illustrated as cautious, dependent, fault finding, shy, and submissive. Style differences between male and female affect the development of thinking methods.

Age: Legislative is generally found in the primary stage, where a child is encouraged to develop their creative powers in the relatively unstructured and open environment of the preschool.

Schooling and occupation: Different schools and occupations reward different styles. As individuals respond to the reward system of their chosen life pursuit, various aspects of styles are feasibly encouraged (Sternberg, 1997).

Parenting styles: What the parent encourages with reward is likely to be reflected in the style of a child. Students are more likely to develop a judicial style if their parents tend to evaluate, compare and contrast, to analyze, to judge things, both concerning the questions the students ask and concerning the answers that are given.

\section{DEFINING MENTAL HEALTH}

According to Johns, Sutton, andWebster (1957) "Mental health means the efficient and harmonious working of the body as a unit with all parts interrelated and interdependent. This implies the integration of the mind, the emotion, and the body. Mental health lies in the interrelations between thinking, feeling, and acting."

The American Heritage Dictionary of the English Language (2003) defines mental health as A state of emotional and psychological well-being in which an individual can use his or her cognitive and emotional capabilities, function in society, and meet the strain of lifestyle.

Kaplan (1971) writes "Mental health involves a continuous adaptation to changing circumstances, a dynamo process where a living reacting being strived to achieve a balance between internal demands and the requirements of a changing environment".

Hadfield (1960) said that "mental health more fully as the full and free expression of all our native and acquired potentialities, in harmony with one another by being directed towards a common endorse of the personality as a whole".

\section{APPLICATION OF LEARNING AND THINIKING STYLES}

The knowledge about learning and thinking styles suggests that it is important to regard all the students as individuals with unique traits and cater to their needs to promote learning and thinking. The harmonious relationship between learning, thinking styles and teaching promotes class efficiency.

Some specific activities are:

a. Discussions groups can be formed where students have access to different or the same learning styles of others.

b. Another activity of role-playing for students to enjoy learning a language can be done. Engagement in acting roles promotes student's bodily or kinaesthetic intelligence. Moreover, role plays enable students to learn and cooperate with partners and willing to communicate with others.

c. The activity of audiotapes played in the class can also be encouraged. It can be followed by various listening, speaking, or even writing tasks. Students can be provided with tasks such as multiple choices, summary writing, note-taking, etc.

d. Writing tasks can be carried out in various forms. Writing the traditionally independent student work can sometimes be done within cooperative groups. Writing can be a wonderful task if it involves group brainstorming, negotiating with group members, and solving disagreements.

The student-centered classes created by such activities enable students to enjoy their learning and thinking styles in the class. These classroom activities promote harmony between teaching, learning, and thinking styles.

\section{CONCLUSION}

For all students, mental, physical, and social health is important and intertwined strands of life. As our understanding of this relationship increases, it becomes ever additional evident that mental health is critical to the general well-being of students, societies, and countries. A student faces several pressures and challenges that create a range of physical, mental, social, and emotional difficulties. As a result of ever-changing the social and emotional image of students, they become additional issues. No analysis exists on the link between students in education and mental health; this is often problematic given the rising numbers of students reporting mental health considerations, one thing which will hinder the success of students placed into education. even so, there exist links to learning, thinking, and mental health that ought to be explored thoroughly to higher understands however instruction will benefit students with mental illness. The learning of a student is additionally influenced by his kind of learning as a result of everybody contains the most popular kind of learning. information of learning methods can facilitate the teacher in delivering effective displays to various learners within the category. thus, an instructor will verify what's best for the students.

\section{REFERENCES}

1. Kanchi Shah, Junaid Ahmed, Nandita Shenoy, Srikant Natarajan (2013) How different are students and their learning styles?

2. Daniela Boneva, Elena Mihova (2012) Learning styles and learning preferences

3. Dr. Sajna Jaleel \& Dr.Anne Mary Thomas (2019) Learning styles theories and implications for teaching-learning

4. Risnanosanti soleh, Ristontowi, Ristontowi towi (2018) Students' thinking styles and their proof-writing levels, Journal of physics conference series

5. Ali Abdi (2012) A study on the relationship of thinking styles of students and their critical thinking skills

6. Li-Fang Zhang (2002) Thinking styles and modes of thinking: Implications for education and research, The Journal of psychology interdisciplinary and applied

7. Francisco Cano-Garcia \& Elaine Hewitt Hughes (2010) Learning and thinking styles: an analysis of their interrelationship and influence on academic achievement

8. Fernando Domenech betoret (2007) The influence of students' and teachers' thinking styles on student course satisfaction and their learning process

9. Mohammadreza Negahi, Naser Nouri, Alireza Khoram (2015) The study of learning styles, thinking styles and English language academic selfefficacy among the students of Islamic Azad University of Behbahan considering their field of study and gender

10. Gue-Hai Chen, Li-Fang zhang (2010) Mental health and thinking styles in Sternberg's theory: An exploratory study

11. Nasrah Mahmoud Ismail (2012) Using learning styles, thinking styles and students attitudes to predict English language achievement at the college level

12. June S. L. Brown (2018) Student mental health: some answers and more questions 